\title{
Parental Opinions and Beliefs toward Use of Psychotropic Drugs for Treatment of Mental Health Problems in Children
}

\author{
Eman Dawood ${ }^{1},{ }^{2},{ }^{3 *}$, Rufa Mitsu ${ }^{1},{ }^{2}$, Haya Al Fozan ${ }^{2},{ }^{4}$, Bashayer Alharbi ${ }^{5}$ \\ ${ }^{1}$ College of Nursing, King Saud bin Abdulaziz University for Health Sciences, Riyadh, Saudi Arabia \\ ${ }^{2}$ King Abdulla International Medical Research Center, King Saud bin Abdulaziz University for Health Sciences, Saudi Arabia \\ ${ }^{3}$ Department of Psychiatric and Mental Health Nursing, College of Nursing, Menofyia University, Egypt \\ ${ }^{4}$ King Saud bin Abdulaziz University for Health Sciences, Riyadh, Saudi Arabia \\ ${ }^{5}$ Undergraduate Nursing Student, College of Nursing, King Saud bin Abdulaziz University for Health Sciences, Riyadh, Saudi Arabia
}

DOI: $\underline{10.36348 / \text { sjnhc.2020.v03i12.003 }}$

| Received: 27.11.2020 | Accepted: 09.12.2020 | Published: 13.12.2020

*Corresponding author: Dr. Eman Dawood

Email: dawoode@ksau-hs.edu.sa

\section{Abstract}

Life of a parents with a child who agonizes from mental illness can be perplexing subsequently they need to have better understanding about the way their child's mental illness presents itself in every life setting, this understanding may provide the foundation for seeking the treatment. Parental opinion and beliefs toward psychotropic drug compliance has a critical value that could improve or worse the course of treatment and the child's mental health outcome. Aim: This study was conducted to assess the parental opinion and beliefs toward use of psychotropic drugs for treatment of mental health problems in children in the central region of the Kingdom of Saudi Arabia. Methods: A descriptive correlation cross section research design was utilized on a sample of 526 Saudi parents who were selected by a random location methodology. Data was collected using two part questionnaire, part one was the demographic data sheet, second part was a modified translated Arabic 16 item scale "parental opinion and beliefs toward use of psychotropic drugs for treatment of mental health problems in children." Description about the purpose and nature of the study was explained to each individual potential participant. Participants were assured confidentiality of the collected data and that it will be used only by the researchers for the purpose of the current study. Data were analyzed using SPSS version 22. Results: Study revealed that half of the parents believed that some psychotropic drugs are dangerous for children. The total participants' responses to the parental opinion and beliefs toward use of psychotropic drugs for treatment of mental health problems in children scale score ranged between 16 and 60 with higher scores indicating more accurate opinions and more favorable beliefs toward psychotropic medication prescription and administration to children. Correlation between selected demographic variables and parental opinion and beliefs toward use of psychotropic drugs for treatment of mental health problems in children, showed a highly statistically significant relationship between parents' opinions and beliefs scores and the age of the parents, furthermore study findings revealed a highly statistically significant difference in the total opinion and beliefs score between participants with different marital status. Conclusion: Fear of psychiatric stigmatization and ignorance of the nature of mental disorders are important factors which influence the opinion and beliefs about psychotropic medication among parents of children with mental disorders, which threatens to rule out psychopharmacotherapy.The study findings showed the need for more education on scientific knowledge regarding the psychiatric treatment methods and its importance in managing psychiatric disorders among children.

Keywords: Psychiatric disorders, psychotropic drugs, parental opinions, beliefs, children.

Copyright (C) 2020 The Author(s): This is an open-access article distributed under the terms of the Creative Commons Attribution 4.0 International License (CC BY-NC 4.0) which permits unrestricted use, distribution, and reproduction in any medium for non-commercial use provided the original author and source are credited.

\section{INTRODUCTION}

Life of a parent with a child who struggles with mental illness can be mystifying. Children who suffer from mental and emotional disorders need parents who will care and support them [1]. Parents should understand the way their child's mental illness presents itself in every life setting such as at home, school, or community settings, this understanding may provide the foundation for treatment and support services to accomplish their child's needs [2].

Family attitude and belief toward psychotropic drug compliance is of a critical value that could improve or worse the course of treatment, therefore, more effective mental health education is needed. Negative attitude or false opinion of the community influence the parent's belief and trust in the 
psychotropic drugs efficacy and therapy. Parent's educational level, socio-cultural values, drug dependency, severity of the child condition, trust in physicians and personal or parental willingness are factors that affect the acceptance and compliance of the psychotropic drugs throughout the course of treatment. Findings of the study by Lazaratou, Anagnostopoulos, Alevizos, Haviara \& Ploumpidis [3], confirmed that $80 \%$ of parents feared from psychotropic medications compared to other medication, $20 \%$ assumed that psychiatrists describe excessive doses of psychotropic medication to their children, $13 \%$ thought that psychotropic medication in general induce harm and danger, but $61 \%$ ultimate the danger to certain types of psychotropic medications.

Social stigma is one of the substantial factor that affect the individual's interest in seeking or complying with psychotropic medication. Individuals choose to seek for mental health services when the condition could not be controlled as a last choice. Financial resources could limit some parents from seeking treatment [4]. Results of the study by Debar, Lynch, Powell \& Gale [5] confirmed that out of 743 preschool children who received treatment at clinics have psychiatric illness, $71 \%$ have other considerable exposure factors inclusive of family history with psychiatric illness or drug addiction, $29 \%$ of the children exposed to abuse and 31\% received foster care. ADHD, Autism Spectrum Disorder, Communication disorders, Intellectual disabilities, Language disorders, Motor disorders are types of neurodevelopmental disorders. These disorders requires early identification and treatment. Psychotropic medication can be taken with all types of patients but it is important to differentiate between medication side effects in children than adults [6]. Parents should be given information about medication compliance and healthy balanced life style during the course of child's treatment. Side effects and complications could be mild or serious, which needs close monitoring and evaluation.

Psychotropic medications are prescribed to manage the emotional and behavioral problems in children who were diagnosed with mental health problems. The psychotropic medication usage in children has been increasing for past 20 years. An optimally trained and qualified person in the use of these medications in this age group should prescribe psychotropic medications [7]. Problems regarding treatment efficacy may influence parents' choice to comply with prescribed medication for their child. There is less empirical evidence to offer adequate help for assessing the usefulness of psychotropic treatment. Even with good compliance, there is no assurance that the treatment was effective [8]. Parents are unconvinced about medication and it is often practiced as a last option [9]. Few parents took their children with problems to the psychiatrist only when they did not know what to do next. Many parents intuited that psychiatrists were too hurried and were over-dependent to prescribe psychotropic medications to their children [10].

Over prescription of psychotropic medication may happen when there is lacking attention to supplementary provisions and amenities that may be a subsidy for treatment in childhood psychiatric disorders. Also under prescription of psychotropic medication may occur when there is less access to any mental health assessment and/or parents were not able to follow-up with mental health treatment. Psychotropic Medications may also be overprescribed or under prescribed when psychiatrist have not had necessary training and practice of psychotropic medications as an approach to manage childhood psychiatric problems. Also it happens when there is less number of psychiatrists specialized in treating children with mental health problems. More over cultural influences and parental preferences represent main concerns in making conclusions about prescribing psychotropic medications. It is important for the psychiatrist to evaluate and identify the parents views and beliefs about psychotropic medication use for their children with mental health problems [7]. Coyle [11] stated that children with behavioral disorders had been enforced to unnecessary pharmacologic treatments, though there is no empirical evidence to rely on psychotropic drug management in children.

In spite of the intense increase in the use of psychotropic medications for children with mental health problems, there is an unexpected scarceness of discussion about the psychological influence of medication on parents and children therefore, parents should be communicated early in the assessment since they may oppose the use of psychotropic medication for their child [12]. Findings of the study by AL-Haidar [13] conducted among 973 participants signposted that, $83.5 \%$ of the parents agreed to give their children psychotropic medication but first they preferred to start with psychological sessions, eldest parents easily accepted giving their children the psychotropic medication, also parents who have used this medications before and having another child with psychiatric disorder influenced the parents acceptance and rejection toward psychotropic medication. $78.3 \%$ reported anxious feeling regarding the drug's sideeffects while $52 \%$ were anxious about the possibility of drug addiction, $71.1 \%$ reported concern about the child age, too young to start psychotropic drug. $74.3 \%$ in case of psychiatric problem would seek advice from psychiatrist rather than using a traditional medicine therapy.

The level of psychiatric prescribing in children and adolescents is increasing; however, rates of compliance in this group of patients range only $34-54 \%$ [14]. Literature scarce information concerning the attitudes and views of the general public and the 
medical community about psychotropic medication. The shortage of research on the usefulness of psychotropic medication on mental disorders of childhood adds to the child psychiatrist's reluctance to put forward drug treatment. The scarcity of studies poses an actual impasse for the child psychiatrist, whether to reject to order a treatment that might ascertain usefulness or to accept obligation for safety [15]. Child psychiatrists were also affected by the existing negative attitudes of the public, and their hesitation, in turn, affects the acceptance of drug treatment by the parents.

Many parents stay generally uncertain to attempt for treatment of their own child mainly due to the misconceptions about psychotropic medications. A common thought among parents who have inadequate knowledge about psychotropic medication is that these medications are not a solution to their child's behavioral problems [10]. These attitudes can lead to less treatment seeking and poor compliance to prescribed treatment, and thereby diminish the usefulness of evidence-based treatments.

Rising evidence shows that predecessors of adult mental disorders can be recognized in children and adolescents [16]. Worldwide 10-20\% of children and adolescents were identified with mental health problems, globally it was estimated that 1 in 160 children has Autism Spectrum Disorder [17]. This can become a major problem for the development of any country. However majority of parents do not prefer to accept psychotropic medication as a treatment for mental health problems in children. Several studies point out that parents are dissatisfied with pharmacotherapy since they were not given complete information regarding the risks and benefits of psychotropic medications [3]. Parental lack of knowledge about the usefulness of psychotropic medications in treating the mental health problems in children can relentlessly impact children's development, their educational accomplishments and their ability to live gratifying and productive lives [18]. The comprehensive mental health action plan 20132020 , accepted by the $66^{\text {th }}$ World Health Assembly has provided a framework for strengthening the abilities in nations to discourse the mental health needs of children and adolescents [18].

Current literature review revealed very few reports regarding the parental opinion and beliefs about use of psychotropic medication in children. Moreover in Saudi Arabia no research evidences are available in this area. Therefore it is mandatory to investigate the parental opinion and beliefs about psychotropic medication use in children among Saudi adults.

\section{SUBJECTS AND METHODS Aim of the Study}

The aim of this study was to assess the parental opinion and beliefs toward use of psychotropic drugs for treatment of mental health problems in children in the central region of the Kingdom of Saudi Arabia.

\section{Specific Objectives}

1. Assess the opinion and beliefs toward use of psychotropic drugs for treatment of mental health problems in children.

2. Assess what concerns parents most about prescribing psychotropic medication to children.

3. Evaluate the relationship between selected demographic variables and opinion and beliefs toward use of psychotropic drugs for treatment of mental health problems in children.

4. Evaluate the relationship between knowing a child suffering from mental disorder and opinion and beliefs toward use of psychotropic drugs for treatment of mental health problems in children.

\section{Setting}

This study took place in various community settings in Riyadh city covering and representing the five regions of Riyadh city (north, south, east, west and center), Kingdom of Saudi Arabia. Settings included: Shopping Malls, Mosques, Saudi Employees of different randomly selected hospitals, outpatient clinic/ laboratory office, Saudi attendants and their relatives at different hospitals, colleges and universities who were selected from the above mentioned public areas in Riyadh.

\section{Study Subjects}

Saudi, adult, male or female parents were included in this study.

\section{Research Design}

A descriptive correlation cross section research design was utilized to conduct this study with the aim to examine the parental opinion and beliefs toward use of psychotropic drugs for treatment of mental health problems in children.

\section{Sample}

A quota sample of 526 Saudi adults with a sample points selected by a random location methodology was selected for the purpose of this study. Subjects were recruited from different Saudi community settings in Riyadh city. To ensure representativeness of the sample, a list of all malls, mosques, colleges, and hospitals in all the five regions of Riyadh city was created. Names was then written separately in small pieces of paper and put into different containers that are categorized and labled as Malls, Mosques, Hospitals, and Colleges. One name was 
blindly selected from each container to ensure randomization. Participants were selected from each location using convenience sampling technique. Principle investigator contacted the appropriate authorities of the proposed settings to obtain appropriate approvals to collect data from those sites before the actual data collection procerdure start. Data collectors who understood about the study purposes and perviously trained on data collection approached the potential participants at the proposed settings and explained the study.

Upon consenting, interview took place when and wherever convenient for the participant. Avaliable subjects were included in the study until the desired sample size was reached.

\section{Data Collection}

Data was collected using a two part questionnaire. Part one was the demographic data sheet which was developed by the researchers which included range of variables such as: gender, age, marital status, level of education, place of residence $\&$ having a child with psychiatric disorder. Second part consisted of a 16 item scale which was obtained and modified from the research study "Parental attitudes and opinions on the use of psychotropic medication in mental disorders of childhood" by Lazaratou, Anagnostopoulos, Alevizos, Haviara \& Ploupidis [3]. The scale measures the parental opinion and beliefs toward use of psychotropic drugs for treatment of mental health problems in children, the questionnaire was adjusted and translated from English to Arabic by the researchers. Content validity of the instrument was assessed by two experts who examined the tool and approved it. Test retest method was used to determine the reliability of the tool, by applying this tool twice with a one week interval on 20 subjects who were excluded from the study. The reliability was 0.89 . Subjects needed $10-15$ minutes to complete the questionnaire. A pilot study was conducted to test the feasibility and applicability of the tool. The pilot study was carried out on five subjects. The result of the pilot study helped in refining the questionnaire form.

A bilingual Arabic-English speaking associate professor in psychiatric nursing had translated the english version of the scale into Arabic version. Back translation was performed by another professional bilingual Arabic-English speaking psychiatric nursing assistant professor. The Arabic version of the questionnaire was piloted on five native Arabic speaking adults to test the feasibility and applicability of the tool.

\section{Data Analysis}

Data was coded for entry and analyezed using SPSS statistical software package version 22. Data was presented using descriptive statistics in the form of frequencies and percentages. Interval and ratio variables were presented in the form of means and standard deviations. Appropriate statistical tests was employed to test the correlation between study variables. The significance level was chosen to be $(\mathrm{p}<0.05)$.

\section{Ethical Considerations}

After obtaining all necessary ethical approvals from College of Nursing-Riyadh (CON-R) research unit and King Abdullah International Medical Research Center (KAIMRC) ethics committees, researchers requested permission from each proposed setting prior to actual data gathering. Research ethics was strictly followed in pursuing the study. Written consent was secured from each potential participant prior to starting the data collection. All information that was collected from the participants was considered highly confidential and no part of this study divulge the identity of the participants or their families.

\section{RESULTS}

Data were collected from various public locations with the aim to assess the parental opinion and beliefs toward use of psychotropic drugs for treatment of mental health problems in children. A total of 526 questionnaires were completed by Saudi parents of children toward use of psychotropic drugs for treatment of mental health problems in children in the central region of the Kingdom diagnosed with different mental health problems. $119(22.6 \%)$ were male and 407 (77.4\%) were females. Participants' age ranged between 22 and 56 years with a mean age of 37.97 and standard deviation of 9.11 years. Regarding marital status of the participants in the current study, $453(86.1 \%)$ were married, 39 (7.4\%) were divorced and $34(6.5 \%)$ were widowed. Analysis of the collected data revealed that the level of education of the participants included in the study ranged between being illiterate and having a doctorate degree as following; almost two thirds of the participants $361(68.6 \%)$ had bachelor degree followed by $135(25.7 \%)$ had diploma degree, 16 (3\%) had master degree, $10(1.9 \%)$ were illiterate and only four participants $(0.8 \%)$ had a doctorate degree. $374(71.1 \%)$ were working while about one quarter of the participants $152(28.9 \%)$ had no job. With regard to the family monthly income, more than half of the participants had a monthly income more than 10000 Saudi Riyals $(n=290,55.1 \%)$, about one third $(n=172$, $32.7 \%$ ) had a monthly income between 5001 and 1000 Saudi Riyals and only $12.2 \%(n=64)$ had an income of 5000 Saudi Riyals or less than per month. Number of family members ranged between three and seven members with a mean family size of $5.15+0.98$ persons in the family and the majority lived in the city $(n=487$, $92.6 \%)$ while only $39(7.4 \%)$ lived in rural areas. 


\begin{tabular}{|l|l|l|}
\hline \multicolumn{1}{|c|}{ Table-1: Sociodemographic data of the participants (n = 526) } & Frequency (N) & Percent (\%) \\
\hline Variable & & 22.6 \\
\hline Gender & 119 & 77.4 \\
Fale & 407 & 86.1 \\
\hline Marital Status & 453 & 7.4 \\
Married & 39 & 6.5 \\
Divorced & 34 & 1.9 \\
Widowed & & 25.7 \\
\hline Education & 10 & 68.6 \\
Illiterate & 135 & 3.0 \\
Diploma degree & 361 & 0.8 \\
Bachelor degree & 16 & \\
Master degree & 4 & 71.1 \\
PhD or equivalent & 374 & 28.9 \\
\hline Occupation & 152 & 12.2 \\
Working & & 32.7 \\
Not working & 64 & 55.1 \\
\hline Monthly Income & 172 & \\
Less than 5000 Saudi Riyals/ Month & 290 & 92.6 \\
5001-10000 Saudi Riyals/ Month & 487 & 7.4 \\
More than 10000 Saudi Riyals/ Month & 39 & \\
\hline Location of Data Collection & & \\
Urban City & & \\
Rural Area & & \\
\hline
\end{tabular}

Children's age ranged between four and sixteen years with a mean child age of $10.85+2.99$ years. Age of the child at the time of diagnosis with the mental health problem ranged between two and ten years with a mean child age of $5.29+1.48$ years. The most common diagnosis reported by almost half of the children $(n=246,46.8 \%)$ was ADHD followed by autism $(n=229,43.5 \%)$, intellectual disability $(n=37$, $7.0 \%$ ). Most of those children were prescribed psychotropic medications to manage their symptoms $(n=491,93.3 \%)$, of those children, less than half of them were taking their prescribed medications regularly $(n=243,46.2 \%)$ while about one third of the parents included in this study sometimes gave their children the prescribed psychotropic medications $(\mathrm{n}=177,33.7 \%)$ and $87(16.5 \%)$ of the parents didn't give their children the prescribed psychotropic medications. When the researchers asked the participants if they believe that psychotropic drugs are dangerous for children, almost half of the parents $(\mathrm{n}=258,49 \%)$ reported that some psychotropic drugs are dangerous while $(\mathrm{n}=201$, $38.2 \%)$ reported that they don't believe that all psychotropic drugs are dangerous and only $37(7 \%)$ reported that all of psychotropic drugs are dangerous. Number of children diagnosed with mental health problems in each family ranged between one and four children with a mean number of affected children of $1.51+0.79$.

Table-2: Children's diagnosis and psychotropic prescription $(n=526)$

\begin{tabular}{|l|l|l|}
\hline Statement & Frequency (N) & Percent (\%) \\
\hline Medical Diagnosis & & \\
Attention Deficit Hyperactivity Disorder (ADHD) & 246 & 46.8 \\
Autism & 229 & 43.5 \\
Intellectual Disability & 37 & 7.0 \\
Learning difficulty & 13 & 2.5 \\
Communication Disorder & 1 & 0.2 \\
\hline Did the psychiatrist prescribe psychotropic medications to treat your child? & & \\
Yes & 491 & 93.3 \\
No & 35 & 6.7 \\
\hline Do you give your son/daughter the prescribed psychotropic medications regularly? & & \\
Yes & & 46.2 \\
Sometimes & 243 & 33.7 \\
Rarely & 177 & 03.6 \\
No & 19 & 16.5 \\
\hline Do you believe that psychotropic drugs are dangerous for children? & 87 & 7.0 \\
Yes, all of psychotropic drugs are dangerous & & 49.0 \\
Yes, some of the psychotropic drugs are dangerous & 37 & 38.2 \\
I don't believe that all of psychotropic drugs are dangerous & 258 & 5.7 \\
I don't know & 201 & 30 \\
\hline
\end{tabular}


Table-3: Participants' opinion on the safety of psychotropic medication $(n=526)$

\begin{tabular}{|l|l|l|}
\hline Statement & $\begin{array}{l}\text { Frequency } \\
(\mathbf{N})\end{array}$ & $\begin{array}{l}\text { Percent } \\
(\%)\end{array}$ \\
\hline Psychotropic drugs may cause damage to the child's health & 316 & 60.1 \\
Yes & 210 & 39.9 \\
No & & 79.8 \\
\hline $\begin{array}{l}\text { Dependence and abuse of psychotropic drugs is more common and among children } \\
\text { Yes }\end{array}$ & 106 & 20.2 \\
No & & \\
\hline Psychotropic drugs affect children' learning abilities & 337 & 64.1 \\
Yes & 189 & 3.9 \\
No & & \\
\hline If started at early ages among children, psychotropic drugs will cause greater problems in the future & \\
Yor those children & 316 & 60.1 \\
No & 210 & 39.9 \\
\hline
\end{tabular}

As presented in Table-3 a considerable proportion of respondents believed that psychotropic drugs may cause damage to the child's health, affecting children's learning abilities and if psychotropic drugs started at early ages among children, it will cause greater problems in the future for those children $(n=$ $316,60.1 \%$ and $337,64.1 \%$ and $316,60.1 \%$ ), more than three quarters of the parents reported that dependence and abuse of psychotropic drugs is more common and easily happening among children $(n=420,79.8 \%)$.

Table-4 illustrates parents' responses to the parental opinion and beliefs toward use of psychotropic drugs for treatment of mental health problems in children scale. Although analysis of the data showed that majority of the parents included in the study had relatively highly accurate knowledge about psychotropic medications as they agreed about the following statements: psychotropic drugs have categories like antidepressants, anxiolytics, hypnotics, and anti-psychotics with different mechanism of action and efficacy $(81.1 \%)$, psychotropic drugs act on the brain correcting a biological abnormality responsible for the mental disease $(64.6 \%)$, psychotropic drugs are effective in managing the symptoms (74.3\%), psychotropic drugs have a common mechanism of action $(86.9 \%)$. On the other hand those parents reported many concerns about administering prescribed psychotropic medications to their children as following; 90.9\% agreed that risks and side effects of psychotropic drugs increases with the young age of the affected children, $81.6 \%$ agreed that taking psychotropic drugs in younger ages would more likely develop drug addiction later in life, $80.8 \%$ reported that psychotropic drugs cause more damage to children because of their young age, $64.4 \%$ agreed that psychotropic drugs cause addiction and $63.7 \%$ agreed that long-term use of psychotropic drugs cause damage to the brain, stomach, kidneys and liver. $64.8 \%$ of the parents preferred drug treatment than electroconvulsive therapy to manage symptoms of mental illnesses.

The total participants' responses to the parental opinion and beliefs toward use of psychotropic drugs for treatment of mental health problems in children scale score ranged between 16 and 60 with a mean scale score of $(42.67+5.53)$ with higher scores indicating more accurate opinions and more favorable beliefs toward psychotropic medication prescription and administration to children.

Table-4: Participants responses to the parental opinion and beliefs toward use of psychotropic drugs for treatment of mental health problems in children scale $(n=526)$

\begin{tabular}{|l|l|l|l|l|l|l|l|}
\hline Statement & \multicolumn{2}{|l|}{ Agree } & \multicolumn{2}{|l|}{ Neuteral } & \multicolumn{2}{l|}{ Disagree } & M+(SD) \\
\cline { 2 - 6 } & $\mathbf{N}$ & $\mathbf{\%}$ & $\mathbf{N}$ & $\mathbf{\%}$ & $\mathbf{N}$ & $\mathbf{\%}$ & \\
\hline Psychotropic drugs cause sedation without curing the mental health problem & 310 & 58.9 & 102 & 19.4 & 114 & 21.7 & $2.51+1.46$ \\
\hline Psychotropic drugs are effective in managing the symptoms & 391 & 74.3 & 39 & 7.4 & 96 & 18.2 & $3.98+1.24$ \\
\hline Psychotropic drugs have a common mechanism of action & 457 & 86.9 & 60 & 11.4 & 9 & 1.7 & $1.76+0.72$ \\
\hline $\begin{array}{l}\text { Psychotropic drugs have categories like antidepressants, anxiolytics, hypnotics, and anti- } \\
\text { psychotics with different mechanism of action and efficacy }\end{array}$ & 427 & 81.1 & 53 & 10.1 & 46 & 8.8 & $4.21+0.97$ \\
\hline $\begin{array}{l}\text { Psychotropic drugs act on the brain correcting a biological abnormality responsible for the } \\
\text { mental disease }\end{array}$ & 340 & 64.6 & 134 & 25.5 & 52 & 9.9 & $3.79+1.10$ \\
\hline Psychotropic drugs cause addiction & & & & & & & \\
\hline Psychotropic drug user will become addicted and therefore be unable to stop taking it & 258 & 64.4 & 127 & 24.1 & 60 & 11.5 & $2.16+1.25$ \\
\hline Long-term use of psychotropic drugs cause damage to the brain, stomach, kidneys and liver & 335 & 63.7 & 183 & 34.8 & 85 & 16.1 & $2.51+1.34$ \\
\hline Psychotropic drugs are dangerous & 346 & 65.8 & 90 & 17.1 & 45 & 8.5 & $2.14+1.06$ \\
\hline Psychiatrists prescribe unnecessarily high doses of psychotropic drugs & 308 & 58.6 & 163 & 31.0 & 55 & 17.1 & $2.17+1.12$ \\
\hline Higher doses of psychotropic drugs are more effective & 223 & 42.4 & 153 & 29.1 & 150 & 28.5 & $2.20+1.04$ \\
\hline Long-term use of psychotropic drugs prevent relapse in patient & 264 & 50.2 & 190 & 36.1 & 72 & 13.7 & $3.59+1.20$ \\
\hline Drug treatment is preferred than electroconvulsive therapy & 341 & 64.8 & 137 & 26.1 & 48 & 9.1 & $3.91+1.10$ \\
\hline Psychotropic drugs cause more damage to children because of their young age & 425 & 80.8 & 83 & 15.8 & 18 & 3.4 & $1.74+0.88$ \\
\hline $\begin{array}{l}\text { Taking psychotropic drugs in younger ages would more likely develop drug addiction later } \\
\text { in life }\end{array}$ & 429 & 81.6 & 73 & 13.9 & 24 & 4.5 & $1.75+0.91$ \\
\hline $\begin{array}{l}\text { Risks and side effects of psychotropic drugs increases with the young age of the affected } \\
\text { child }\end{array}$ & 478 & 90.9 & 39 & 7.4 & 9 & 1.7 & $1.51+0.71$ \\
\hline
\end{tabular}


To examine the correlations between selected demographic criteria and parental opinion and beliefs toward use of psychotropic drugs for treatment of mental health problems in children, Pearson $r$ showed a highly statistically significant relationship between parents' opinions and beliefs scores and the age of the parents $(\mathrm{r}=.116, \mathrm{p}=0.00)$, age of the child $(\mathrm{r}=.88, \mathrm{p}$ $=0.04)$, age of the child when diagnosed $(r=.211, \mathrm{p}$ $=0.000$ ), number of children diagnosed with mental health problem in the family $(r=.198, p=0.000)$, while the number of the family members had relationship with the parental opinion and beliefs toward use of psychotropic drugs for treatment of mental health problems in children $(\mathrm{r}=.024, \mathrm{p}=582)$. Kendall's tau test was conducted to test the correlations between parental opinion and beliefs toward use of psychotropic drugs for treatment of mental health problems in children and parent's level of education, monthly income and if s/he gives the son/daughter the prescribed psychotropic medications regularly. Kendall's tau test showed only statistically significant negative relationship between the monthly income and the opinions and beliefs total score $(\mathrm{r}=-.216, \mathrm{p}=0.000)$. One-way ANOVA revealed a highly statistically significant difference in the total opinion and beliefs score between participants with different marital statuses $(\mathrm{F}=18.790, \mathrm{p}=0.000)$ with divorced parents having higher mean scores compared to married and widowed parents $(47+2.19,42.53+5.61,39.53+4.18)$ consecutively.

Table-5: Relationship between selected demographic criteria and parental opinion and beliefs toward use of psychotropic drugs for treatment of mental health problems in children $(n=526)$

\begin{tabular}{|l|l|l|}
\hline Demographic Criteria & \multicolumn{2}{l|}{ Psychotropics Opinion and Beliefs } \\
\cline { 2 - 3 } & r & P \\
\hline Age of the parent & $.116^{* *}$ & 0.008 \\
\hline Age of the child & $.088^{*}$ & 0.044 \\
\hline Age of the child when diagnosed & $.211^{* *}$ & 0.000 \\
\hline Number of children diagnosed with mental health problem in the family & $.198^{* *}$ & 0.000 \\
\hline Number of family members & .024 & 0.582 \\
\hline Level of education & -.015 & 0.667 \\
\hline Monthly income & $-.216^{* *}$ & 0.000 \\
\hline Do you give your son/daughter the prescribed psychotropic medications regularly? & -.048 & 0.164 \\
\hline
\end{tabular}

Independent sample $\mathrm{T}$ Test was conducted to test the difference in the opinion and beliefs mean scores between different groups, $\mathrm{T}$ test showed no differences in the opinion and beliefs scores among parents from both genders (male mean score= $43.36+3.98$, female $=42.47+5.98, \mathrm{t}=1.55, \mathrm{p}=0.121)$, employment status (employed mean opinion and beliefs score $=42.84+5.70$, not employed $=42.24+5.08, \mathrm{t}=1.14$, $\mathrm{p}=0.253$ ), if the psychiatrist prescribed psychotropic medications to treat the child (yes $=42.80+5.53$, $\mathrm{no}=40.68+5.25, \mathrm{t}=2.01, \mathrm{p}=0.045)$.

In studying the differences in the mean opinion and beliefs scores among parents who expressed different concerns related to administering psychotropic medications to their young children, $\mathrm{T}$ Test for independent samples revealed statistically significant differences in the mean scores of the parents who concerned more that psychotropic medication would result in damaging the child's health and if psychotropic drugs started at early ages among children it will cause greater problems in the future for those children (yes=44.36+5.29, no=40.13+4.87, $\mathrm{t}=9.262, \mathrm{p}=0.000$ ). While no difference in the mean opinion and beliefs score was detected between parents who believed or not that children may get used to psychotropic drugs easily and parents who believed or not that psychotropic drugs affect children' learning abilities $(t=0.667, \mathrm{p}=0.505)$.

\section{DISCUSSION}

Psychotropic medications are prescribed as a part of treatment for emotional and behavioral health problems in children and adolescents althought a minority of children and adolescents with psychological problem seek treatment. In this study our major findings demonstrated that parents have more accurate opinions and more favorable beliefs towards psychotropic medication prescription and administration to children.

Among 526 parents who participated in this study, most of their children received psychotropic medication for mainly common psychiatric disorders like, attention deficit hyperactivity disorder and autism. A similar study conducted by Abid, Hamdani, Shafique and Aadil [23] revealed that most common child psychiatric disorders were epilepsy, behavioral disorders, conversion disorders and mental retardation. Most of those children were prescribed with psychotropic medications but only few of them were complying to the prescribed medication, on the other hand one third of the parents seldom gave their children the prescribed psychotropic medications and many of the parents didn't help their children comply with the prescribed psychotropic medication. While the reason for noncompliance was found to be psychotropic drugs are dangerous, few agreed that they don't believe that all psychotropic drugs are dangerous. Number of children diagnosed with mental health problems in each family ranged between one and four children. This finding when compared with Garfield, Brown, Allaire, Ross, Nicol and Raghavan [19] they explained that psychiatric disorders are common among childhood. While many problems can be treated without drugs, some conditions require pharmacotherapy. Most 
psychotropic medications prescribed for children has not been tested and approved by the Food and Drug Administration for use in this age group. Medications are not routinely tested in young children; yet, close clinical monitoring of children receiving psychotropic drugs is acceptable until clinical trials establish their safety and usefulness in this population.The evidence base for the efficacy of pharmacological treatments in preschool children is limited [20].

Regarding parents opinion on the safety of psychotropic medication almost half of the parents reported that psychotropic medication causes harm to their children while few reported that not all drugs are dangerous and there were also parents who acknowledged that psychotropic medications are compeletely unsafe for their children. This finding could be compared with the study conducted by Lazaratou, Anagnostopoulos, Alevizos, Haviara and Ploumpidis [3] who indicated that a significant proportion of parents have negative opinion on psychotropic medication, most parents have a greater fear concerning their children taking psychotropic medication than for other types of medication.

A significant proportion of parents in this study believed that psychotropic drugs might lead to certain issues in children's life such as, problems with learning, psychotropic drugs started at early ages of the child possibly might cause problems in the future, and also have a fear about dependence and abuse of psychotropic drugs among children. All medications have side effects; it is important to decide whether to consume the medication requires knowledge of both the likelihood of benefit as well as the risks of harm from taking a medication. Usually, any medication should be granted FDA approval when it is found to be safe and effective for a particular diagnosis for people of a specific age group as determined by evidence based research [21]. Similarly, the research carried out by Lazaratou, Anagnostopoulos, Alevizos, Haviara and Ploumpidis [3] revealed that majority of parents believed that psychotropic drugs are dangerous, but a clear variation was found among them, only few believed that all psychotropic drugs are dangerous, while $61 \%$ agreed that some group of medication is dangerous. Two-thirds of the parents believed that psychotropic medication cause addiction for antipsychotics, antidepressants, anxiolytics and hypnotics, while $23 \%$ did not express any opinion. Another study by Pappaport and Chubinsky [12] explained that although parents without having a second thought give cough medicine or antibiotics, they are fearful and anxious to give psychotropic medication that have effect on abnormal behavior and thinking of children diagnosed with problems. Parental reluctance to adhere to the prescribed psychotropic medication may intervene with the treatment [22].
Parental opinion and beliefs in this current study toward use of psychotropic drugs for treatment of mental health problems in children revealed more positive opinions and believes concerning psychotropic medication prescription and administration to children. Majority of parents acknowledged that they have knowledge about most of the psychotropic drugs including its mechanism of action and its side effects. Parents conveyed that psychiatrists preferred other treatment options like psychotherapy and electroconvulsive therapy (ECT) than medications. In contrast the study done by Abid, Hamdani, Shafique and Aadil [23] $80 \%$ of parents had an opinion that psychiatrics never over prescribe psychotropic medications. Two third of the parents were anxious and worried of giving psychotropic medication for thier children. Many parents expressed concern that if they agree to put their children on psychotropic medication, there will be a risk of later substance abuse. There is no scientific evidence to support this belief. In fact, there is evidence that children with ADHD who are prescribed with stimulants are actually at lower risk of subsequent substance abuse, when compared to children with ADHD who are not prescribed stimulants [24]. Abid, Hamdani, Shafique and Aadil [23] discovered an inspiring verdict that a huge group of parents agreed that psychotropic drugs have a therapeutic effect on the brain which helps in altering the biological factors that causes the disease. But at the same time nearly half of the parents had a belief that psychotropic drugs have an addiction potential and that they might damage the vital organs. FDA has disseminated caution that stimulants like Ritani leads to addiction, depression, insomnia, drug dependence, mania, psychosis, heart problems, stroke and sudden death. Side effects are the major concern for parents, more evidence-based research is required specifically concerning prescription of psychotropic medications for children and adolescent group. But undeniably benefits outweigh these risks [21].

Parents' opinions and beliefs in this study revealed highly statistically significant relationship with the age of the parents, age of the child, age of the child when diagnosed, number of children diagnosed with mental health problem in the family Lazaratou, Anagnostopoulos, Alevizos, Haviara and Ploumpidis [3] found no correlation between parental opinion and age of child, the proportion of parents who agreed with the limitation to administer psychotropic medication for children who are under special medical prescription increased as the age of the child increased. Precisely, $20 \%$ of the parents with children aged 2-7 years, $50 \%$ with children aged 7-12 years, and $75 \%$ with children aged older than 12 years responded that they agree with this limitation. Abid, Hamdani, Shafique and Aadil [23] investigated the likely differences in parental opinion and beliefs concerning to the duration of illness of child. As duration of illness increased, parents had a thought that psychotropic drugs will cause more 
tranquility than cure, they are perilous, and probable to cause addiction in the future. There was no significant correlation between Parental opinion beliefs and educational level of parents but Lazaratou, Anagnostopoulos, Alevizos, Haviara and Ploumpidis [3] revealed that parents' beliefs significantly differ according to their educational experiences and the proportion of negative responses increased as the educational level increased.

A highly significant difference in the total opinion and beliefs score between participants with different marital statuses was confirmed with divorced parents having higher mean scores compared to married and widowed parents, but no differences was found in the opinion and beliefs among parents from both genders. This result was reverse with the research done by Lazaratou, Anagnostopoulos, Alevizos, Haviara and Ploumpidis [3] they discovered a dissimilar response between both gender, men responded more negatively than women. A significant difference was found between parents who were concerned that psychotropic medication would result in damaging the child's health and administering psychotropic drugs at early ages would cause greater problems. Another opinion expressed by Wilens, Faraone, Biederman and Gunarwardene [24] that psychotropic medications cause dependency and physical damage, when administered over a long period of time, and that they cause alterations of personality.

\section{CONCLUSION AND RECOMMENDATIONS}

Study results indicated that parental opinion and beliefs toward use of psychotropic drugs for treatment of mental health problems in children has now reached a point that parents'openions and belives are not consistent with the current scientific knowledge. Even though some parents have a positive opinion still there is a need for better understanding about the appropriate use of psychotropic drugs along with psychotherapy. Fear of psychiatric stigmatization and ignorance of the nature of mental disorders plays a major role, which impends to rule out psychotropic medications as a way of treating certain childhood mental health disorders. Having the correct information allows parents to make an knowledgeable decision about whether they should agree to seek and adminster psychotropic medications to their aqffected children. Child psychiatrists have to scientifically apprise the parents on the usefulness and safety of psychotropic medications, and then take into consideration the opinions and beliefs of the family. By considering the perceptions, fears and beliefs of both parents and their affected children psychiatrists will be able to ensure compliance to psychotropic treatment.

\section{Based on the Findings of this Study, the Following Recommendations are suggested}

Clinical research is necessary to investigate the most effective approaches of prevention, early intervention, and treatment of complex mental health needs of children and adolescents. Comprehensive behavioral health assessment has to be done while planning to prescribe psychotropic medication to children and adolescents. Conducting psychoeducational sessions for parents on scientific knowledge regarding the psychiatric treatment options and its benefits. Psychotropic medication can be administered with combined use of an evidence-based psychosocial intervention to manage different menmtal health issues among children.

\section{FUNDING}

This research was funded by grant from King Abdulla International Medical Research Center, National Guard Health Affairs. RC17/053/R - Parental Opinion and Beliefs Toward Use of Psychotropic Drugs for Treatment of Mental Health Problems in Children

\section{CONFLICT OF INTERESTS}

The authors declare that they have no conflict of interests with any organization regarding the materials discussed in this manuscript.

\section{ACKNOWLEDGMENT}

The authors would like to extend their thanks and appreciations to all participants who voluntarily participated in the study and shared their experience.

\section{REFERENCES}

1. DeCubellis, T., Harris, V. W., \& Gillen, M. (2015). My Child Has a Mental Illness: Developing Parental Advocacy Skills. Youth and Community Sciences Department, EDIS, http://edis.ifas.ufl.edu.

2. Clark, L. R. (2012). Personal communication, EDIS, university of Florida, IFAS extension, family youth and community sciences.

3. Lazaratou, H., Anagnostopoulos, D. C., Alevizos, E. V., Haviara, F., \& Ploumpidis, D. N. (2007). Parental attitudes and opinions on the use of psychotropic medication in mental disorders of childhood. Annals of General Psychiatry, 6(1), 32.

4. Aloud, N., \& Rathur, A. (2009). Factors affecting attitudes toward seeking and using formal mental health and psychological services among Arab Muslim populations. Journal of Muslim Mental Health, 4(2), 79-103.

5. DeBar, L. L., Lynch, F., Powell, J., \& Gale, J. (2003). Use of psychotropic agents in preschool children: associated symptoms, diagnoses, and health care services in a health maintenance organization. Archives of pediatrics \& adolescent medicine, 157(2), 150-157.

6. National institute of mental health. (2016). Transforming the understanding and treatment of mental illnesses. National institutes of Health. 
7. American Academy of Child and Adolescent Psychiatry. (2007) Practice parameter on child and adolescent mental health care in community systems of care. J Am Acad Child Adolesc Psychiatry, 46:284-299.

8. Jensen, P. S., Arnold, L. E., Swanson, J. M., Vitiello, B., Abikoff, H. B., Greenhill, L. L., ... \& Conners, C. K. (2007). 3-year follow-up of the NIMH MTA study. Journal of the American Academy of Child \& Adolescent Psychiatry, 46(8), 989-1002.

9. DosReis, S., Zito, J. M., Safer, D. J., Soeken, K. L., Mitchell, J. W., \& Ellwood, L. C. (2003). Parental perceptions and satisfaction with stimulant medication for attentiondeficit/hyperactivity disorder. Journal of Developmental and Behavioral Pediatrics, 24(3), 155-162.

10. Olaniyan, O., dosReis, S., Garriett, V., Mychailyszyn, M. P., Anixt, J., Rowe, P. C., \& Cheng, T. L. (2007). Community perspectives of childhood behavioral problems and ADHD among African American parents. Ambulatory Pediatrics, 7(3), 226-231.

11. Coyle, J. T. (2000). Psychotropic drug use in very young children. JAMA, 283:1059-60.

12. Pappaport, N., \& Chubinsky, P. (2000). The meaning of psychotropic medications for children, adolescents and their parents. J Am Acad Child Adolesc Psychiatry. 39(9), 1198-2000.

13. Al-Haidar, F. (2016). Parental attitudes toward the prescription psychotropic medications for their children. Journal of Family and Community Medicine, 37.106.187.193.

14. Waterman,Y., Hales, L., \& Glackin, M. (2015). Prescribing for children and adolescents in mental health. Published online.

15. Tsiantis, J. (2000). The challenges of child psychiatry in the rising of new millennium [in Greek] Paediatriki, 63:186-190.

16. World Psychiatric Association; World Health Organization; International Association for Child and Adolescent Psychiatry and Allied Professions. (2005). Atlas: Child and Adolescent mental health resources,
http://apps.who.int/gb/ebwha/pdf_files/WHA66/A 66_R8-en.pdf?ua=1 retrived on 01/10/2017.

17. World Health Organization. (2016). Autism Spectrum Disorders. Fact sheet. http://www.who.int/mediacentre/factsheets/autism -spectrum-disorders/en/ retrived on 01/10/2017.

18. World Health Organization. (2017). Child and adolescent mental health. http://www.who.int/mental_health/maternalchild/child_adolescent/en/ retrived on 01/10/2017.

19. Garfield, L. D., Brown, S. D., Allaire, B. T., Ross, R. E., Nicol, G. E., \& Raghavan, R. (2015). Psychotropic Drug Use Among Preschool Children in the Medicaid Program From 36 States. Am J Public Health, 105(3): 524-529.

20. Zito, J. M., Derivan, A. T., Kratochvil, C. J., Safer, D. J., Fegert, J. M., \& Greenhill, L. L. (2008). Child and adolescent psychiatry and mental health. Child Adolesc Psychiatry Ment Health. 2(1):24.

21. American Academy of Child and Adolescent Psychiatry. (2012). A Guide for Public Child Serving Agencies on Psychotropic Medications for Children and Adolescents. https://www.aacap.org/App_Themes/AACAP/doc s/press/guide_for_community_child_serving_agen cies_on_psychotropic_medications_for_children_ and_adolescents_2012.pdf Accessed October 25, 2020.

22. Hack, S., \& Chow, B. (2001). Pediatric psychotropic medication compliance: a literature review and research-based suggestions for improving treatment compliance. J Child Adolesc Psychopharmacol, 11:59-65.

23. Abid, H., Hamdani, S. U., Shafique, F., \& Aadil, M. (2018). Psychotropic Medication in Mental Disorders of Childhood, Pak Armed Forces Med J. 68(1): 131-136.

24. Wilens, T. E., Faraone, S. V., Biederman, J., \& Gunarwardene, S. (2003). Does stimulant therapy of attention deficit hyperactivity disorder beget later substance abuse? A meta-analytic review of the scientific literature. Pediatrics. 111(1):179185. 